International Journal of Management Science and

Business Administration

Volume 2, Issue 8, July 2016, Pages 16-23

DOI: $10.18775 /$ ijmsba.1849-5664-5419.2014.28.1002

URL: http://dx.doi.org/10.18775/ijmsba.1849-5664-5419.2014.28.1002

\title{
Managerial Skills and Corporate Strategic Planning
}

\author{
Kellen Kiambati ${ }^{1}$, Julius Itunga ${ }^{2}$ \\ ${ }^{1}$ Lecturer, Karatina University, P.O. BOX 1957 - 10101, Karatina, Kenya \\ ${ }^{2}$ Water Services Regulatory Board, P.O. BOX 4162-0010-GPO, Nairobi, Kenya
}

\begin{abstract}
The aim of this study is to establish the relationship between managerial skills and corporate strategic planning. The study was premised on increased call to meticulous strategic planning in all organizations across all sectors in Kenya. A close examination of existing literature showed that very little has been done in the area of evidence-based strategic planning. Public and private institutions participated in this study. The findings showed a positive and significant relationship between managerial skills and corporate strategic planning. The implication of the findings for management is to give more attention to managerial skills.
\end{abstract}

Keywords: Corporate strategy, Managerial skills, Strategic planning

\section{Introduction}

The word strategy has multidimensional view and diverse definitions from various scholars. Drucker (1954) viewed strategy as an answer to dual questions regarding the type of business firms engages in and the intended business activities. Chandler (1962) advanced Ducker's definition by incorporating the how of achieving an organization's intention. Chandler (1962) considered strategy as a process of determining the basic long-term goals and objectives of a firm, adopting courses of action and finally allocating resources necessary for carrying out these goals. In explaining strategy, Andrews (1971) considered both Ducker's and Chandler's views and postulated that strategy is the pattern of objectives, purposes, goals, major policies and plans for achieving them with strategy as a unifying tool. Those who share this perspective define strategy regarding the unity of purpose and the direction it gives to the firm (Ansoff 1965, Quinn 1980). Mintzberg (1973) defined strategy as the patterned stream of decisions focusing on a set of resource geared towards achieving certain objectives in an uncertain environment.

Hofer and Schendel (1978) considered strategy as systems that enable firms to increase market share, achieve sustainable growth and turn around the fortunes of the business. Wernerfelt (1984) introduced the resource perspective and defined strategy regarding the resource position of the firm. Mintzberg (1987) argued that a single definition of strategy cannot suffice. He then proposed five different definitions of strategy. According to him, a strategy is a plan, a ploy, a pattern, a position and a perspective. As a plan, strategy specifies a consciously intended course of action of an organization. As a ploy, a strategy is seen as a maneuver geared towards outdoing a competitor. As a pattern, a strategy is seen as a pattern emerging in a stream of actions. The strategy develops in the absence of intentions. As a position, the strategy is a means of locating an organization in its environment. Lastly, as a perspective, strategy consists of a position of an ingrained way of perceiving the world for organization identity.

Porter (1980) thoughts on strategy have been supported by precision research and have remained consistent and developmental over decades. Using the value chain, he described the primary activities of business as those concerned with transforming inputs into outputs while secondary activities support primary functions. To be able to survive competition, a firm has to ensure that all these value-chain activities link together and fit into the environment. A weakness in any activity will impact on the chain as a whole and affect competitiveness and the overall strategy. To examine its competitive capability in the marketplace, an organization must choose between three generic strategies of cost leadership, differentiation, and focus. These generic strategies are driven by five competitive forces related to the power of customers, the power of suppliers, threat of substitute products and rivalry within the industry. Strategy rests 
on unique activities based on customer needs and company products. Therefore, according to Porter (1996), a strategy is the act of positioning a business in a given industry through an analytical process.

Whittington (1993) introduced four generic approaches to strategy. These are the classical approach, evolutionary approach, processualists approach and the systemic approach. The classical approach considers strategies as outcomes of rational analysis, evolutionary approach holds that strategy making is a competitive process where only the best ones survive, processual approach view strategy as an emergent process of learning and systemic approach believes in the ability of an organization to plan forward and act effectively within their environment. According to Johnson and Scholes (2005) strategy is the direction and scope of an organization over the long term. It achieves an advantage for the organization through its configuration of resources within a changing environment. A well-formulated strategy should meet the needs of markets and fulfill expectations of stakeholders. A strategy thus consists of the means an organization chooses to move from its present state to its future. A strategy thus consists of the means an organization chooses to move from its present state to its future position.

Strategy development takes place at three different levels within an organization according to scope and function. These are the corporate level, the business level and the functional level (Ansoff, 1965; Pearce \& Robinson, 1988; Johnson \& Scholes, 2005). The three distinctive strategic levels are clearly discernible in organizations involved in several businesses capturing different market segments. Hax \& Majluf, (1984) postulated that at the corporate level, organizations engage in the formulation of vision, mission, strategic posture and identification of Strategic Business Units (SBU), resource allocation, budgeting and definition of performance measurements. At level, the business focus moves to the strategic business groups regarding identification of business scope, products, and market segments. At functional level firms engage in the formulation of functional strategies, a definition of specific action programs and budgeting. In a nutshell, strategy theorists agree on three main areas in the study of the concept of strategy. First, they agree that strategy includes both the actions taken by managers, content of a strategy and the process upon which the actions are decided. Second, there is general agreement that deliberate, emergent and realized strategies may differ in formulation but seek to achieve the same objective. Third, a business entity may have corporate, business and functional strategies at the same time. Finally, scholars concur that the making of strategy is a conceptual, intellectual as well as an analytical exercise. However, areas of disagreement relate the formation and appropriateness of strategy in different environmental contexts.

\section{Literature review}

\subsection{Generation of Strategy}

The strategy generation debate has not gained consensus. Many questions still arise as to where strategy comes from and how do firms find themselves with strategy. Gavetti et al (2005) asserted that there is a tension in originating strategy. Managers struggle to understand their environment. Accordingly, the origin of strategy has a dual nature; it exists in the mind of the managers and is orchestrated by their experience in the world of their firms. Porter (1985) pointed out that strategy is embodied in activities of firms. March, Schltz and Zhuo (2000) agreed that strategy embodies in routines and firm rules. From the position school to the evolutionary school managers are driven by cognition and the world of action (Winter, 2003; Porter, 1980). Firms being highly plastic conform to reality and managers can only shape them to the desired posture. Solutions and strategy bundles can be sought from the vicinity of a problem, considering an incremental change to existing concurrent trials and errors. Rumelt (2009) took note that strategy making was most critical in times of change and unfamiliar environments. This assertion agreed with Wiltbank et al (2006) who stated that to create a strategy for a firm that was doing well was difficult. Strategy generation depends on the given uncertainty.

In such encounters, organizations may rely on two schools, namely the planning school and learning school. The planning school is attributed to Ansoff (1979) as a systematic analysis and integrative planning avoiding short cuts such as intuition and heuristics which suffers from personal and group biases (Wiltbank et al, 2006). Systematic planning helps to overcome inconsistencies though prediction remains obviously difficult. However, Grant (2003) did not support these views arguing that in dynamic environments planning slows down adaptation and makes organizations blind. The learning school is attributed to Mintzberg and Waters (1985). The predictive rationality for quick responses to uncertain events leads to emergent strategy. According to Markoczu (2001), strategy generation is an incremental process that involves consensus building and is multifaceted. Strategy is an outcome of a rational decision-making process. So to originate strategy takes into consideration versatility through mazes of boundary spinning fields and how 
they intertwine with organizational elements. Whittington (1993) introduced four approaches, namely the classical, evolutionary, procession and systemic approaches. The four differ fundamentally on the process by which strategy is made and its outcomes. According to the classical approach, a strategy is made through rational analysis and under the evolutionary approach strategy emerges to enable firms to achieve a fit in competitive environments. According to Giovani and Rivkin (2007), the genesis and dynamics of business strategy remain a profound puzzle.

Strategy content is defined by Andrews, Boyne and Walker (2003) as the patterns of service provision that are selected and implemented. Strategy content comprises two dimensions, namely strategic stance and action. Stance is the extent to which an organization searches for continuous realignment with its changing environment, selects positions for competitiveness or responds to changes to pick new orientations altogether. Strategic stance is the broad way in which an organization seeks to maintain or improve its performance. Strategic action is the relative emphasis on changes in market, services, revenues, external relationships and internal characteristics. Strategic actions are the specific steps that an organization takes to operationalize its stance. Zajac and Shortell (1989) were of the view that the level of strategy is relatively enduring and unlikely to change substantially in the short term. However, Fox, Boal, and Hunt (1998) were of the contrary view asserting that these strategic options are more likely to change in the short-term. Strategy content, therefore, refers to how organizations behave, in contrast to a strategy which is merely rhetorical and immeasurable.

Firms must realign to the environment in their strategy content designs and develop controls that shape strategy during implementation. Managers should be aware that invalid assumptions and environmental changes are two main reasons that a strategy being implemented fail. Tenets of content integrate with evaluating the underlying assumptions on which strategy was built and monitoring the process of implementation in the wake of changing the environment (Muralidharan, 2004). While strategies are based on information meant to be true as well as assumptions about relationship and phenomena, the ration of assumptions to knowledge underlying strategies will vary. Similarly, while environments of all businesses are bound to change, the rate of change will vary across industries. This is the perspective of strategy context. Configurations of strategy with other elements within these contexts consume substantial managerial time and resources. Muralidharan (2004) emphasized that being proactive is essentially needed. In competitive environments firms must be ready to act and react; strategy must be seen as a cross-functional tool consistent with the context of the organization benefiting from the feedback loop of the unfolding environment.

\subsection{Strategy Process}

Another aspect of strategy pointing to its configurations with structure and resource capabilities is the of managing strategy that can be explained by an array of conceptual models, dimensions, and typologies. Butler (2002) advocated for the rational analytical approach. This has been recognized as a central aspect of strategic decision making. It has been intensively subjected to both theoretical and empirical investigation. This approach involves managers using various tools of analysis and methodologies to make critical decisions. Its holistic view is similar to the planning mode of Mintzberg (1987). The advocates of this approach favor formal planning systems, management control, and consistent reward mechanisms to increase the quality of strategic decisions. On the other hand is the political behavior approach which espouses a powerful behavioral force to strategy formation. It assumes that decisions emerge from a process in which decision makers have different aims, forming alliances to achieve their goals in which the preferences of the most powerful prevail. This model rests on executive bargaining, negotiation and networking and the practice of muddling through the strategy making process. The last approach is the logical instrumentalism which views both the rational and the behavioral processes as being integrative.

These approaches fit into the three modes of entrepreneurial, adaptive and planning that were illustrated by Mintzberg (1987). For entrepreneurs, the strategy is developed by an individual (CEO) who relies on intuition, experience and personal judgment in formulating strategy. In the adaptive mode, strategy formulation is characterized by muddling through a variety of issues while the planning mode involves analyses and anticipating the future. This does not differ much from dimensions named as command, symbolic, rational, transitive, and generative by Hart (1992). Each mode reflected a pattern of interaction between the roles of top managers and organizational members, representing a resource or skill set available to the firm. Mintzberg and Waters (1985) posited that strategies emerge from a set of inconsistencies and processes. Whittington (1993) did not differ much from this perspective in his own proposed approaches. The systemic approach focused on the internal context of the organization embedded in micro-politics, social groups, interests, and resources. Accordingly, he asserted that in competitive environments, the best strategy is selected by the environment, not managers. In a world too complex and full of surprises to predict, the strategist needs 
to retain closeness, awareness, and adaptability. Though these views do not contradict in any way, they raise pertinent questions of what the real process is in any given firm context. As noted already these are theoretical conceptualizations that have received low empirical grounding.

\subsection{Strategy models}

In strategic management literature, a few models of strategy have dominated the debate. Prominent studies confirm the Miles and Snow typology (Wayna, et al, 2005), the Porters generic forces model (Porter, 1980) and the emergent strategy model (Mintezberg and Waters, 1985). Recently, however, a host of intermediary archetypes and taxonomies have gained acceptance. Hunt (2000) acknowledged that the Porter model had generated intensive debate though its empirical validity was at times difficult to comprehend. There are interpretations where strategies are hierarchically ordered or strategy designs emerging from data sets within which positions are attained (Miller, 1986). Porter's (1980) notion was that firms may achieve competitive advantage by positioning themselves in structurally profitable industries and strategic groups. Acquaah and Masoud (2008) revisited the generic strategies of differentiation, cost leadership and focus and reaffirmed their endurance in explaining firm behavior.

According to Wyna et al, (2005) the 1978 typology of Miles and Snow has been widely embraced. The framework has four strategy perspectives namely, prospector, analyzer, defender and reactor strategies. Wayna, et al (2005) attributed the longevity of this model to having addressed the industry interdependent nature. This view agreed with Hambrick (2003) who argued that the Miles and Snow typology was the most enduring strategy classification. The prospectors undertake technical innovation and seek new markets; the analyzers seek a second and better strategy while defenders maintain secure niche and stability. The reactors have no stable strategy, are only responsive to environmental exigencies. Kaban off and Shane (2008) posited that whichever strategy model the firm follows, the managers have to deal with three domain issues namely, entrepreneurial (product, market decisions), engineering (production, delivery) and administrative (structures, rules, procedures). Farjoun (2002) regretted that strategy field had suffered a growing separation between prevalent analytic and prescriptive models and the new concepts in descriptive ideas. Strategic planning is, therefore, one distinctive process of articulating strategy. However, there are many disturbances that strategic planning faces in light of the environment. There are forces contained in both the internal and external factors that influence and impact upon the process.

\subsection{Managerial Skills}

Boone \& Kurtz (1999) define management as the process of achieving organizational objectives through people and other resources. This means that management has a lot to do with enterprises human and other resources. Smit \& Cronje (2002) define management as the attainment of enterprises goals in an effective and efficient manner achieved through planning, organizing, leading and controlling the enterprises' resources. Management is a form of work that involves coordinating an organization's resources - land, labor, and capital - toward accomplishing organizational objectives (Rue \& Byars, 1992).

Rue \& Byars (1992) further discuss five functions of management: Planning is deciding what objectives to pursue during a future period and what to do to achieve those objectives; Organizing is grouping of activities, assigning activities, and providing the authority necessary to carry out the activities; Staffing is determining human resource needs and recruiting, selecting, training, and developing human resources; Leading is directing and channeling human behavior toward the accomplishment of objectives; Controlling is measuring performance against objectives, determining the cause of deviations, and taking corrective action where necessary.

\subsubsection{Planning}

A plan is a blueprint specifying the resource allocations, schedules and other actions necessary for attaining goals. Planning is the act of determining the organization's goals and the means of achieving them (Daft, 1997). A goal is a desired future state that the organization attempts to realize. In order to plan effectively, managers need a sound knowledge, the relevant skills, and the right value orientation to apply the planning principles successfully. Effective planning will help a manager to set a clear vision (Graves \& Thomas, 2006). Randel \& John (2001) observe that an approach of mapping out the strategies and structures is needed to make a business run smoothly. Randel \& John (2001) further note that proper strategic plans are practical and applicable methods of striking a balance between business and individual needs. 


\subsubsection{Organizing}

Organizing is the process of creating a structure for the organization that enables its people to work effectively towards its vision, mission, and goals (Greenberg, 1990). Organizing is an indispensable function in the management process. Plans devised and strategies formulated will never become a reality if human and other resources are not properly deployed and the relevant activities suitably coordinated (Wanous, 1972). The major task in organizing is to develop an organizational design that will support the strategic, tactical, and operational plans of the organization. Distelberg \& Sorenson (2009) suggest that developing an organizational design entails grouping the organizational members into work units, developing an integrating mechanism to coordinate the efforts and determining the extent to which decision making in the organization is centralized or decentralized (the locus of decision making).

\subsubsection{Leadership}

Daft (1997) defines leadership as the use of influence to motivate people to achieve a firm's goals. Leading is creating a shared culture and values, communicating goals to human resources in the whole enterprises and infusing the said human resources with the desire to perform highly. It involves motivating the entire firm's human resources. Rue \& Byars (1992) define leadership as the ability to influence people willingly, follow one's guidance or adhere to one's decisions. A leader is one who obtains followers and influences them in setting and achieving objectives. Smit \& Cronje (2002) define leadership as human (symbolic) communication, which modifies the attitudes and behaviors of others in order to meet group goals and needs. Johnson (1999) observes that organizations should have a vision, a mission statement, core values, and goals. It should also have a structure in place for effective decision making. It should equally have clear strategies and plan of action to achieve these goals. Hackman \& Johnson (2009) view leadership as a fundamental element of the human condition.

\subsubsection{Communication Skills}

Communication is key in managing family businesses. A manager needs information for decision making. Ability to disseminate and receive information is, therefore, an important tool for a manager (Dana, 2008). Stech (1983) observes that it is not only verbal communication, but the manager should be able to distinguish non-verbal signals, mood, and feelings to filter the right information. Michaud (1999) offers strategies, such as regular meetings and behavioral process analyses, and then tells how to apply these concepts with minimal effort. In this paper, we argue that managerial cognition drives strategic action. Given the continued debate of what strategy really is and how it is formulated, it turns to the skills of the manager to shape what he takes to be a strategy and what to be pursued as goals. Management skill and relationship with other factors in the organization are very critical. In light of the debate in the extant literature, the following hypotheses were formulated to guide this study.

H1: Organizations are not significantly involved in corporate strategic planning.

H2: There is relationship between managerial skills and corporate strategic planning

\section{Methodology}

This study adopted an analytical cross-sectional design with a view of seeking the relationship between managerial skills and corporate strategic planning in the public and private organization in Kenya. A survey population was considered adequate. This study used a population of senior managers attending a Senior Leadership Seminar. This approach in surveys has been found appropriate in previous studies with enriching findings (Wong and Elankumaran, 2009) \& Hill, Block and Buggie (2000). The senior managers in the seminar were from public and private organizations. From a total of 296, a sample of 169 was taken based on tables developed by Bartlett, Kotrlik and Higgins (2001) in their sample determination formula. A total of 102 questionnaires were received back giving a response rate of 59.81\%. Only 61 Questionnaires were used in data analysis as the rest were incomplete.

\subsection{Response rate}

Table 1.1: Response rate

\begin{tabular}{llll}
\hline Questionnaires distributed & $\begin{array}{l}\text { Questionnaires } \\
\text { Returned }\end{array}$ & $\begin{array}{l}\text { Response rate in } \\
\text { Percentage }\end{array}$ & $\begin{array}{l}\text { Complete } \\
\text { questionnaires } \\
\text { used in } \\
\text { analysis }\end{array}$ \\
\hline 169 & 101 & $61 \%$ & 61 \\
\hline
\end{tabular}


Babbie (2002) observes that a response rate of 50\% is adequate for analysis; hence $59.76 \%$ response rate in this study was adequate for analysis.

\subsection{Sample Configuration}

$60 \%$ of the respondents were from the public sector and $40 \%$ from the private sector. Regarding the size by the number of employees, $70 \%$ of the organizations had numbers above 100 . The respondents who had worked for over ten years were the majority at $80 \%$ against $20 \%$ who had not worked in those organizations for more than a decade. $82 \%$ were in top management positions, $18 \%$ in supervisory roles. This distribution was appropriate to provide insights regarding corporate strategic planning mostly undertaken by top managers

\section{Analysis}

Descriptive statistics sought to find views on the strategic planning process and activities. All the organizations indicated that they had a vision and mission statements however only $60 \%$ could remember contents of the two. $60 \%$ indicated strategic planning was done every five years while $40 \%$ of it was done every three years. This was consistent with the contemporary way of strategic planning where organizations are adopting three years as opposed to traditional five years given the dynamic environment. $69 \%$ indicated that strategic plans were developed by external consultants. In $58 \%$ of the organizations, there was a policy on evaluation of strategic plans, $62 \%$ evaluation was done by top management and $38 \%$ where strategic plans were not reviewed.

Table 1.2: Model Summary of Managerial Skills/Corporate strategic planning Model

\begin{tabular}{lcccc}
\hline Model & R & R Square & Adjusted R Square & $\begin{array}{c}\text { Std. Error of the } \\
\text { Estimate }\end{array}$ \\
\hline 1 & $0.670 \mathrm{a}$ & .448 & .438 & 6.442 \\
\hline
\end{tabular}

The linear regression analysis (model $\mathrm{Y}=\beta 0+\beta 1 \mathrm{X} 1+\mathrm{e}$ ), shows a strong relationship. $\mathrm{R}=0.670$ and $\mathrm{R}^{2}=0.448$ which shows that $44.8 \%$ of the corresponding change in corporate strategic planning can be explained by a unit change in managerial skills. $55.2 \%$ can be explained by other factors not in this model. A further test on the beta coefficient of the resulting model, was not significantly different from 0 , since the $p$-value $p=.657$ is greater than $p=0.05$. $R$-squared $\left(\mathrm{R}^{2}\right)$ - coefficient of determination in linear regression relationship, tells how well the regression line fits the data. It is an important indicator of the predictive accuracy of the equation. The goodness of fit refers to how well the model fits the data(Anderson, Sweeney, \& Williams2002). The model corporate strategic planning= $\beta$ (Managerial skills) holds as suggested by the test above. This confirms that there is a positive linear relationship between Managerial skills and corporate strategic planning.

Helfat and Peteraf (2003) defined resources as assets which a firm owns, controls and has access to on a semipermanent basis. They exist in the form of brand names, trade contacts, technology, skilled personnel and production/service delivery procedures. Dutta et al. (2005) defined capabilities as the efficiency with which a firm employs a given set of resources (inputs) at its disposal to achieve certain objectives (output) in the strategic plan. Ethiraj, Krishinan \& Jitendra (2005), in a study of Indian software industry concluded that the debate should shift from what capabilities are to how capabilities matter in strategic planning. Samson (2007) in a study of knowledge capabilities reaffirmed that when firms accumulate resources, it is natural that their proper utilization is supported by the structures in place.

\section{Discussion}

Our findings confirm that Kenyan organizations are significantly involved in strategic planning. Research has shown that meticulous corporate strategic planning produces better results that wait and see and trial and error method. An off (2001) argues that more attention has been put on the process rather than strategic planning systems. By evaluating the level of strategic planning and how it integrates with managerial skills we share the thoughts.

Our findings reveal low knowledge of the mission and vision among staff and less integration in work processes. The confirmation that external consultants are used in developing strategic plans and involved in evaluation in some 
organizations and that are they are not used revealed that strategic planning is considered an internal function and external as well. Organizations should build internal managerial capacity to undertake strategic planning and do not rely on external skills. Management participation has been found necessary for organizational performance but needs to be integrated across the organizational structures for effectiveness. From the study strategy, the formulation is a premise of top management, but the implementation is emphasized in the lower structures. This has far reaching implications for practitioners. Scholars argue that 40 per cent of the planned value never get achieved due to implementation challenges Mankins and Steele (2005).

We recommend further studies preferably case studies which are comparative in nature, focusing on 100 per cent use of consultants, private and public sector approach to strategic planning. This will help document what has worked and what has not worked.

\subsection{Limitations of the study}

This study had some limitations. We took note of the fact that the respondent managers were involved in the study while attending a course; this may have had some attendant biased responses. Possibly their responses might have been different if we had approached them individually from their organizations. We also relied on each manager to report about their respective organization of work; we did not extend our investigation to seek alternative views from other senior managers in those organizations neither did we control of the likely event that two or more course participants were working in the same organization. We contend, however, that this study has made a contribution body of knowledge in as far as managerial skills and corporate strategic planning are corned and especially in the context of less developed countries.

\section{References}

- Babbie, E. (2002). The Practice of Social Research. Belmont, BC Wadsworth.

- $\quad$ Boone, L. E. \& Kurz, D. L. (1999). Contemporary Business. 13th (Ed.), USA: John Wiley \& Sons, Inc.

- $\quad$ Daft, D. L. (1994).Management. 3rd (Ed.), Fort Worth, TX: Dryden Press.

- $\quad$ Barney, J.B. (1991) Firm resources and sustained competitive advantage. Journal of Management, 17(1), 99-120, CrossRef

- Barraba, V.P. (2004). Surviving transformation. Lessons from GM's surprising turnaround. New York, NY: Oxford University Press.

- Chatterjee, S., \& Wernerfelt, B. (1991) The link between resources and type of diversification: Theory and evidence. Strategic Management Journal, 12, 33-48, CrossRef

- Chowdhury, S.D. (2007). Turnarounds: A stage theory perspective. Canadian Journal of Administrative Science, 19 (3), 249-266, CrossRef

- Christensen, C.M., \& Raynor, M.E. (2003).The innovator's solution: Creating sustaining successful growth. Boston, MA: Harvard Business School Press.

- $\quad$ Cooper, D.R,\& Schindler, P.S. (2006) Business Research Methods.8th Edition, McGraw- Hill, Tata.

- Dana T. (2008). Making the Family Business Work. Oak Brook, IL: Associated Equipment Distributors, Inc

- Dess, G.G., Lumpkin, G.T., \& Eisner, A.B. (2008).Strategic management: Text and cases (4thed). Singapore: McGraw Hill.

- $\quad$ Duta, S., O.M. Narasimhan \& Rajiv, S. (2005). Conceptualizing and measuring capabilities: Methodology and empirical application. Strategic Management Journal. 26. 277 - 285, CrossRef

- Distelberg, B. \& Sorenson R. L. (2009).A Focus on Values, Resource Flows, and Adaptability. New York: HarperCollins.

- $\quad$ Ethiraj, S., K, P. Kale, M.S. Krishinan \& Jitendra V. Singh (2005). Where do capabilities come from and how do they matter. A study in the software services industry. Strategic Management Journal. 26. 25 - 45, CrossRef

- $\quad$ Graves, C. \& Thomas, J. (2006). Internationalization of Australian Family Businesses: A

- Helfat, C. E., \&Petaraf, M. A. (2003). The dynamic resource based view: Capability life cycles. Strategic Management Journal, 24, 997 - 1010, CrossRef

- J. E. Bartlett, J. W. Kotrlik and C. C. Higgins, "Organizational Research: Determining Appropriate Sample Size in Survey Research," Information Technology, Learning, and Performance Journal, Vol. 19, No. 1, 2001, pp. 43 - 50. 
- Michaud, L. (1999). Family Business Communication: From the Kitchen Table to the Conference Table. London, UK: Business Design Centre.

- Johnson, S. C. (1999). A Family Hands Down its Heirloom. New York, USA.

- M. Mankins and R. Steele, "Turning Great Strategy into Great Performance," Harvard Business Review, Vol. 83 No. 7, 2005, pp. 65-72

- Greenberg, J. (1990). Organizational Justice: Yesterday, Today \& Tomorrow. Journal of Management, 16, 399432, CrossRef

- Gould, B.W and K.A. Carlson (1998) "Strategic management objectives of small manufacturers: a case study of the cheese industry" Review of Agricultural Economics 20 (2): 612-630, CrossRef

- $\quad$ Kombo D. K. \&Trom D. L. A. (2006). Proposal and Thesis Writing. Nairobi, Kenya:

- $\quad$ Lawrence, J.D., V.J. Rhodes, G.A. Grimes and M.L. Hayenga (1997). "Vertical Coordination in the U.S. Pork Industry: Status, Motivations, and Expectations" Agribusiness 13 (1): 21-31, CrossRef

- Mahoney, J.T., Pandian, J. R. (1992) The resource-based view within the conversation of strategic management. Strategic Management Journal, 13(5), 363-380, CrossRef

- Neuman, W. L., (2000). Social Research Methods: Qualitative and Quantitative Approaches. Boston: Allyn and Bacon Publishers, CrossRef

- $\quad$ Penrose, E.T. (1959) The Theory of The Growth of The Firm. John Wiley \& Sons, Inc., New York, NY.

- $\quad$ Rue, W. L. \&Byars, L. L. (1992). Management Skills and Application. 6th Edition, Richard, USA: Irwin INC.

- $\quad$ Stech, E. L. (1983). Leadership Communication. Chicago: Nelson-Hall.

- Smit P. J. \& Cronje J. G. (2002). Management Principles. Capetown, South Africa: Juta Publishers.

- Sanchez, R., Heene, A. (1997) Competence-based strategic management: concepts and issues for theory, research, and practice', in Heene, A. \& Sanchez, R. (Eds.).Competence-Based Strategic Management. Chapter 1, 3-42. Wiley \& Sons, New York.

- Sanchez, R., Heene, A., Thomas, H. (1996) Introduction: Towards the theory and practice of competence-based competition. In R. Sanchez, A. Heene, \& T. H. (Eds.), Dynamics of competence-based competition: Theory and practice in the new strategic management: 1-35, CrossRef

- $\quad$ Shrestha, N.R., McKinley-Floyd, L., Mtwige, B. (2008), "Management in Africa in the Global Context", Journal of African Business, (in press), Vol. 9 No.1, CrossRef

- Wong, F. Long and S. Elankumaran, "Business Stu- dents' Perception of Corporate Social Responsibility: The United States, China and India," Corporate Social Responsibility and Environmental Management, Vol. 17, No. 5, 2009, pp. 299-310, $\underline{\text { CrossRef }}$ 